\title{
What Student Positions can be Created on the LBUSD Board of Education to Increase the Effectiveness of Stu- dent Representation?
}

\author{
Emily Hardesty ${ }^{1}$ \\ ${ }^{1}$ Long Beach Poly High School, Long Beach, California, USA
}

\begin{abstract}
$\underline{\text { ABSTRACT }}$
The Long Beach Unified School District Board of Education and superintendent make efforts to have student representation in the decision making process. However, there are many shortcomings in the student representation structure of the LBUSD BOE. The systems set in place do not encourage consistent and active student participation, and evaluations of recent student board member involvement show minimal to no participation. By comparing LBUSD to other CORE school districts, there are clear differences in the way students are represented on the BOE. Notably, many CORE school districts elect student BOE members and include a Student Advisory Council to advise the Board. Other CORE school districts have experienced valuable student participation with their models. LBUSD can draw from other CORE school districts to create a system of student representation on the BOE that fosters student involvement and values student voice.
\end{abstract}

\section{Introduction}

The Long Beach Unified School District facilitates 85 schools in Long Beach, Lakewood, Signal Hill, and Avalon (LBUSD). LBUSD enrolls 71,800 students from k-12 in 85 schools and is made up of a diverse student body which includes: 57\% Latinx, 12\% African American, 12\% White, 7\% Asian American, 3\% Filipino, 1\% Pacific Islander, $0.2 \%$ Native American/ Alaska Native, 15\% English Learners, and $65 \%$ of students are considered economically disadvantaged (LBUSD, 2020).

Along with the Sacramento, San Francisco, Garden Grove, Fresno, Los Angeles, Oakland, and Santa Ana school districts, LBUSD is a CORE district (CORE districts, 2020). This collaboration between districts was meant as a way to share a data system, hold themselves accountable for reporting progress, identify and support schools in need of assistance, and allow schools to learn from each other. These districts are united in a belief of equity and access for all students. To further this commitment LBUSD has implemented a Strategic Plan that aims to "ensure equitable opportunities for every student" and "provide a safe, welcoming, respectful, and rigorous learning environment for every member of the school community" (LBUSD, 2020).

Though unlike LBUSD, a majority of CORE districts have a more extensive structure of student representation on their Board of Education. Sacramento, San Francisco, Garden Grove, Fresno, and Los Angeles have a student Board member in addition to some form of a student advisory council for the Board. The positions held by students in these districts are determined on an elected/appointed basis and students have set terms and responsibilities. This is not the case in LBUSD. However, all school districts do acknowledge the importance and value of the student voice. 


\section{Literature Review}

\section{California Student Board Representation}

\section{California Law}

The state of California has taken more measures to ensure the inclusion of students on school boards, and in 1975 a non-voting student was able to sit on the State Board of Education (Fletcher, 2002). Currently, that role is now a position with full voting rights (Fletcher, 2002).

The California Education Code was amended to create an explicit procedure of creating a student board position in any school district in California. The procedure allows students to petition a school board for a student member with a petition consisting of 500 signatures or at least ten percent of the district student population (Cal Leg Info, 2017). A student board member is guaranteed preferential voting rights within the California Education Code (Cal Leg Info, 2017). The board may grant the student the power to motion, which would allow students to introduce agenda items, table debate, postpone debate, and motion for other procedural actions (Cal Leg Info, 2017). The student board member will be elected by their peers in a procedure determined by the governing board (Cal Leg Info, 2017).

\section{California School Boards Association}

The California School Boards Association hosts a student board member program in which students can collaborate and learn about working in a governance team and looking through a policy lens (CSBA, 2019). According to Myell Jenkins, manager in CSBA's Association Education department, "It's important to encourage authentic participation of student board members and really pay attention to the student board member voice and not just tokenize them - they have a valid viewpoint that can help inform how the school board governs their district." The CSBA recommends that boards give student board members opportunities to attend training, workshops, and conferences.

\section{Creating Effective Student Representation}

\section{What Youth Engagement is and Why it is Important}

Youth engagement should ensure that young people are "involved in the structure and decision making processes of government" and that the engagement is "continuous, representative and meaningful" (Youth Affairs Council, 2016). By increasing engagement, students feel valued and can express their ideas, increases confidence in institutions and encourages participation, and increases student knowledge of institutions and the policy-making process (Youth Affairs Council, 2016). The viewpoint of students is essential on a school board to increase effectiveness of a school board and provide an outlet for student advocacy (PTA). It is also important that student voice is authentic (Benner, 2019).

\section{How to Increase Youth Engagement}

When adults engage with young people it is important that they are accessible, genuine in their purpose, and create a relationship (Youth Affairs Council, 2016). To aid student success it is necessary to keep students informed of what their contribution has done. For students to actively engage, they need the skills necessary to complete a task and a support system (Youth Affairs Council, 2016). When implementing students on governing boards, it is important that those students represent diverse populations and that meetings are accessible (Benner, 2019). There are different levels of youth engagement that can be easily conceptualized with Hart's ladder (Youth Power). There is no engagement when students are tokenized. The highest form of engagement involves cooperative decision making. A similar spectrum of student voice can be visualized by an adaptation of figures by Toshalis and Nakkula, and Mitra and Gross (Benner, 2019). At the lowest end are students who give their opinions. That could be students speaking at a Board 
meeting or sending an email to district staff. On the highest end, students would be in leadership roles making decisions alongside adults. That role could be filled by student board representatives.

\section{Benefits of Youth Representation}

Having students on school boards ensures that students are heard and increases the effectiveness of school improvement measures (Fletcher, 2014). Having students represented among district leadership makes students feel like they are a valuable member of their community which makes them less likely to drop out (Prichard Committee, 2016). Actively engaging students in the policy-making process can contribute to higher performance (Fletcher, 2014). While there are many ways to increase student engagement, implementing students into policy-making creates a system in which students are equal to adults in the decision making process and creates an inclusive environment for students to participate (Benner, 2019). Additionally, when students "buy-in" to their school system, self-efficacy is increased (Prichard Committee, 2016). Students take a greater interest in their own education, which leads to higher performance (Prichard Committee, 2016). Students who have high self-efficacy are also more likely to engage other students through things like student organizations and town hall forums (Prichard Committee, 2016). When students are genuinely engaged, they are more successful.

\section{Method}

This research was done with a mixed method approach using qualitative and quantitative approaches. Data was collected from published school information and interviews with various stakeholders.

I determined that I would gather information from other CORE school districts. These schools have similar belief systems and demographics. I reached out to board members from the districts of: Sacramento, Fresno, Santa Ana, Garden Grove, and San Francisco. I sent them an email that included a standard list of questions, in some cases I had to send follow-up emails asking for clarification and others requested a phone interview. All interviews, email and phone, were conducted with the same list of questions with some deviation for the sake of clarification. With this data I was able to create a description of the Board of Education student representation structures. That information included whether or not the district had a student Board member, other student committees to the board, the process for selecting student representatives, and the success and shortcomings of each system as described by the interviewee. I also emailed student Board members from those districts with a list of standard questions. From that, I made notes on the trends I saw with the data.

To better understand LBUSD's current student representation structure, I interviewed Superintendent Steinhauser who has been in his position for eighteen years. The purpose of this interview was to understand past student board member structures in LBUSD and the current system. Then taking a more empirical approach, I watched recorded Board of Education meetings to observe the actions of the student board member. Prior to watching these meetings I created a chart of certain actions like voting, making a motion, giving a board member report, and contributing to debate. When I observed a student board member doing one of those actions, I would check that box off. I watched the most recent videos going back to February 20, 2019 to observe the recent actions of student board members and determine the recent effectiveness of the student board member. I also emailed past LBUSD student board members to gain their perspective on the role they played. Using the data I had collected, I observed the benefits and shortcomings of LBUSD's current system and compared it to other school districts. From all the information I had gathered, I created a new structure of student representation on the LBUSD Board of Education.

\section{Findings and Analysis}

\section{School Comparisons}




\section{Fresno Unified School Districts}

Student representation on the Fresno Board of Education consists of two student board members and a Student Advisory Board (SAB). The SAB has been in existence for over fifteen years and consists of two to three students from each high school in the district that are chosen by student leadership at their high school (Mills, 2020). The SAB meets the day before every board meeting at one of the Fresno high schools to discuss the agenda items, proposed policies and initiatives, and district-wide student projects. The board uses the SAB to provide input on district initiatives and policies before adoption. Student board members are elected from the SAB by the SAB. The student board members serve for a year-long term and participate in all board meetings except closed sessions and vote on items of the public agenda. Students also serve on many district committees, and in particular a student representative was on the advisory committee to choose a new superintendent. Fresno board member Carol Mills stated that the student voice has "had a significant impact on our board policies, most recently on equity and access, and dress code modifications; and has influenced initiatives, such as allocation of school facility bond money."

\section{San Francisco Unified School District}

San Francisco also has a two tier model of student representation to the Board: two student board members and a Student Advisory Committee (SAC). The SAC is a team of around fifty high school students that assist the student board members and are involved in a multitude of school and district committees and projects (Lopez-Barreras, 2020). Members of the SAC are chosen by a system determined by their school which is usually done in two ways: a school site election or SAC application which includes a vetting and interview process done by the SAC Cabinet team. The student board members are also selected in two ways. One student is chosen through a district-wide election and the second is elected by the SAC. Student board members represent 56,000 students and attend the bi-monthly board meetings who are intended to provide student input, insight, and voice. The SAC also has bi-monthly meetings separate from the Board of Education meetings. Student board members have a preferential vote and all student delegates have the power to author and co-author resolutions and legislation brought to the board. Students have been involved in creating resolutions to support undocumented students and ensure all students have bathroom access. This system allows students to develop skills in service to become better representatives. This system allows students to "occupy roles of leadership and advocacy" where they can recognize "a duty and area of need which they can occupy to manifest a tangible change they wish to see make happen," as stated by Salvador Lopez-Barreras, the Student Leadership and Advisement Engagement Supervisor for San Francisco unified school district.

\section{Garden Grove Unified School District}

Garden Grove follows a structure of student representation that the California School Board Association recommends. This includes a student board member and a Board Representative Committee (McAmis, 2020). The student board rep at the time of application must be a current junior in high school with at least a 2.0 GPA. Two students-- including current BRC members-- from each high school may apply, and each high school can determine the process by which the two student applicants are chosen. All qualified applicants are then interviewed and selected by the Intra-District Council which consists of high school leaders. After being selected the student will serve for a year-long term from July 1 to June 30. Student board representatives have responsibilities that include: attending all board meetings except closed sessions, to carry out the duties of a non-voting member of the board, and to represent student interests at board meetings. The member receives training for their role and has the opportunity to attend a state-level meeting and speak with other student representatives. A previous GGUSD student board member described this experience as an "opportunity to discuss and find out what solutions worked, and what didn't" and use the student perspective to compare district policies and projects (Student X, 2020). She also summarized her position as an opportunity "to see the inner-workings of the policy and the process of what determines the education and environment I receive every day" and as a "platform to voice any concerns that other students or [she] may have" (Student X, 2020). The student member also serves as the chair for the BRC and attends board meetings to provide input on agenda items. The BRC consists of one student from each district high school, and members attend monthly meetings and are 
given various presentations from district faculty. Members may ask questions and provide input on district initiatives and can review the board agenda. The meeting is open to BRC members with the Superintendent, Assistant Superintendent, and the Director of 7-12 Instruction are in attendance. The Assistant Superintendent also oversees the BRC. In conjunction with these meetings, BRC members are given "homework" that requires them to consult district stakeholders as a way of making sure members can adequately represent the student population. The BRC was recently involved with the GGUSD wellness campaign that supports socio-emotional well-being. The current Assistant Superintendent, Kelly McAmis, considers the current student representation system to be successful and well-received by the district (McAmis, 2020). The current system of student representation for GGUSD is one in which students can engage with the district and the district engages with students.

\section{Sacramento}

The student board member in Sacramento serves on the Board of Education and is elected by the Student Advisory Council (SAC) and must be a current junior (Minnick, 2020). The SAC is made up of students from each of the Sacramento high schools. Typically those running will go through an application process and give a speech to the SAC. Student board members have a preferential vote as required by California Education Code. However, this vote does not go towards the official vote count, and Sacramento Board member Michael Minnick stated that he would be open to allowing the student member "a legal vote on items that are not related to Human Resources or Final Budget." Member Minnick expressed that the student member has influence on the board, but their vote rarely changes the outcome of the final vote. However, during a previous search for a new superintendent the student board member was given a legal vote for the selection of the superintendent.

\section{Schools in Comparison}

Every school evaluated in this research is a CORE school. Schools not included in this research but are a CORE school include: Los Angeles Unified, Santa Ana Unified, and Oakland Unified. From the schools not researched, LAUSD does have a student board member whereas Santa Ana does not. The schools that were researched in this study all had a form of official student representation to the board. Every school also followed a similar dual representation model which consists of a student board member and some variation of a student committee that advises and assists the board. The method by which these students are selected varies, however, in every school selection process students vote in some capacity to elect their representatives. This process is one in which students are involved and invested in. A student board member within LBUSD stated that being a board member allows her to connect students "to the district in a way that exposes them to the great things that the district is making an effort towards." Student board representation should be a system for students by students. All of the schools evaluated in this research recognize the value of official student representation positions and Salvador Lopez-Barreras justified the San Francisco structure as a way for students to possess "a voice in decision making processes [to] invest themselves in a nonreplicable way to their own community, and because of that, are able to work towards constructing a sustainable and self-sufficient world." The Santa Ana school district does not have a student board member but Member Valerie Amezecua has "been asking for two years" to have a student member. Ultimately, all schools believe the student voice is invaluable and has the capability to improve the school district.

\section{Amending Student Representation on the LBUSD Board of Education}

\section{Evolution of the LBUSD Student Board Member}

About fifteen years ago, LBUSD had a "traditional" student board member (Steinhauser, 2020). Thes student would serve a year-long term and was chosen through an election and interview process. This system received criticism for the lack of opportunity it gave other students to act in an advisory capacity to the Board. With this structure there was an issue of student board members having difficulty attending all meetings, and student board members kept coming from the same few schools: Milikan, Poly, and Wilson. To address some of these concerns, the student board 
member position was amended to only serve for a semester, yet many of the same problems remained. Within the last ten years, LBUSD changed to its current system of rotating student board members.

\section{The Current System}

Student representation in LBUSD is typically informal. LBUSD runs on a model of seeking out the student voice from as many students as possible to be able to serve in an equitable manner, and schools and the district create a multitude of opportunities for students to become involved in the implementation of new board projects and policies. Students can come directly to the board like one student did to express concern about the school idling policy which resulted in an idling ban (Steinhauser, 2020). The superintendent does quarterly school walk-throughs and student groups lead district workshops and hold panels for students to give advice to district leadership. The superintendent has an advisory committee made up of two to four students from every high school that are selected by the school and meets with them twice a year (Steinhauser, 2020). On this committee a Millikan student had presented research on how to reduce vaping in high schools, and that student's research caused the installation of vape detectors in high school bathrooms (Steinhauser, 2020). The overarching theme of student representation in LBUSD is that all students, of all levels should be able to participate.

One of the more high-profile student representation positions is the student board member. This student gets to attend a board meeting, sit with the Board members, and speak during the meeting. LBUSD is on a rotating student board member system which means a different high school is represented at each meeting (Steinhauser, 2020). This student is selected by their school and is usually an ASB leader. Prior to the meeting the student is given the agenda and a member of the superintendent's staff will help them review the items, and the superintendent and board members will introduce themselves to the student member prior to the meeting. The student board member will lead the pledge of allegiance and give a report on their school's activities during the board member report section of the meeting (LBUSD BOE). The student has the capability to voice their opinion during discussions and, according to the superintendent, can vote on some agenda items. A previous student board member of the 2019-20 school year described the position as a time to explain what is going on at his/her school and hoped "to influence our board members and prove that we are the flagship high school of Long Beach" (Student Y, 2020).

\section{The Current System's Flaws}

In theory, the student board member is meant to be an equitable solution to give students from all high schools the opportunity to represent their student body on the Board. In practice, the student board member is a figurehead position that, because the position is rotating, does not serve the purpose of consistently advising the board and acting as a strong source of student voice.

While the position is meant to represent all high schools within the LBUSD district, between February 20, 2019 and January 22, 2020 the high schools represented on the Board were: Renaissance, CAMS, SATO, Browning, Cabrillo, Jordan, Wilson, Poly, Milikan, Lakewood, Cabrillo (LBUSD BOE). Within this time, some schools were represented twice. Those include: CAMS, SATO, Renaissance, and Jordan. Out of fourteen high schools, eleven were represented. In total there were twenty Board meetings within this time span, and there was a student board member at fifteen of those meetings. Note that students do not serve on the Board during summer break, winter break, or spring break.

During Board meetings from June 10, 2019 to February 20, 2020 student board members only spoke during the board report section of the agenda (LBUSD BOE). These reports consisted of updates on school construction, dances, faires, sports, new faculty, and their work with the community. Nothing stated was critical of LBUSD and rarely sparked discussion among the board members. While students members can speak during discussion, none of them did, and even though they can vote on some agenda items, none of them visibly voted. Following the students' reports, the president of the board would ask them two general questions: "are you a senior?" and "do you plan to attend college, and do you have a major in mind?" Only on one occasion was a student asked their opinion on what was discussed during the meeting (Boe video: January 8, 2020). However, even this question was posed after the 
official discussion time for agenda items. In all other meetings, board members never consulted the student member or asked them any questions. In one instance, two board members began loudly opening food as the student member began their report. Evidently in this instance the student's report was not seen as a valuable opportunity to listen to student input, but was rather regarded as a "break" from the actual meeting (Boe video: February 5, 2020). The student board members' involvement, in actuality, is limited to leading the pledge and giving a report, yet the student's picture is used as the thumbnail for online published Board meetings, and members often make comments about the importance of having a student board member. There is a disparity in the intended and actual involvement of the student member, and because of this, the student board member position is one of tokenism. These students are not acting as board members, and when asked, the superintendent could not recall any policies or projects recent student board members had proposed.

In more recent news, all LBUSD schools were shut down for the remainder of the 2019-2020 school year due to threats posed by COVID-19. An announcement that LBUSD school would be closing for five weeks was made Friday, March 13, 2020. This closure was done quickly and via a mass district email in which teachers were given no advanced notice. On Saturday, March 14, 2020, an emergency Board of Education was held (Boe video: March 14, 2020). All five board members were in attendance and no student board member was present. Due to the urgent nature of this meeting, there could have been no time to coordinate the inclusion of a student, or the board did not consider having a student present at all. The discussion of this meeting surrounded the effects of school closures and the measures being taken to fulfill student needs, yet there were no students present. A big question presented during the meeting was how to administer educational instruction. This is a question in which the student perspective could have been extraordinarily helpful. One board member brought up how important spring is for high school seniors because of the tests they are meant to take-- especially the SAT. While spring is important for seniors in regards to AP preparation and scholarship applications, seniors do not take the SAT in the Spring. This statement made by a board member shows the limitations of the board members' knowledge of what learning looks like in schools. If the structure had been in place for a permanent student board member position, a student could have given valuable insight into the concerns of students during this emergency situation.

\section{New Structure Proposal}

Keeping in mind the lack of actual influence the student board member position has in LBUSD, a structure needs to be adopted that ensures that student representatives have a secured and formal platform for voicing their opinions. Drawing from other school districts, LBUSD can adopt a student board representation structure that includes student board members and a student advisory committee. Like other districts, the Student Advisory Committee (SAC) can consist of two students from every high school and will be selected in a manner determined by the school site. That could include campus-wide elections or an application and selection process, but preferably a combination of both. It would also be preferable if schools mandated that one of their SAC positions be held by a rising senior. The selection of student representatives would also happen towards the end of the school year so students may begin their term the following June. LBUSD should have two student board members to avoid tokenism and to make the student members more comfortable speaking on a board of adults. The simplest way to select the student board members would be to allow the Student Advisory Council to elect them. This eliminates the possibility of only electing students from large high schools through district-wide elections because every school is equally represented in the SAC. In terms of qualifications and responsibilities, the student board members would follow a set of terms outlined in California Education Code.

A majority of CORE districts use this type of structure and have found it effective. In comparison, the current system for the student board member in LBUSD does not serve its purpose as a source of student advisement. This could be largely due to the fact that these members are present to the board once, and for some students, twice. Being a representative is a skill, and it is a skill that is developed over time. The Garden Grove school district has a thorough approach to preparing their student representatives, and this is a system that should be considered and implemented for any future student board representatives in LBUSD. Adult board members and district faculty should be invested 
in the development of student representatives. San Francisco and Garden Grove have a dedicated staff for student engagement that oversees student board representatives. In the case of LBUSD it may be more feasible to adopt Garden Grove's method of having the Assistant Superintendent oversee student board representatives than potentially taking on new staff or creating a new department within LBUSD. Garden Grove even gives student representatives "homework" that is meant to help them understand district stakeholders and the implications of district policies. These students are being taught how to represent students in an ethical and equitable manner.

Another common practice of other districts is to hold separate meetings for their student advisory council. In attendance are executive district staff and the student representatives. Students are provided with new and critical district information and can review Board meeting agendas. This is a setting where many students can give informed opinions on district matters, and this can also be used as a time to prepare the student board members for a board meeting. In terms of LBUSD, it would be logical to hold a meeting prior to a board meeting so students can become informed on the items that will be discussed and can consult their constituency before attending the board meeting.

\section{Conclusion}

\section{Summary \& Limitations}

The current student board position in LBUSD does not serve its purpose. A student board member is meant to advise and provide opinions on district initiatives. Instead student board members give updates about their schools that can be informative but have no substantial weight on board discussions. However, this conclusion is drawn from viewing Board of Education Meetings rather than the opinion of student Board members.

Instead, LBUSD can adopt a structure similar to other CORE districts and implement two student board members and a Student Advisory Council. This system includes all high schools and maintains equitable representation and also trains students to be skilled and informed in their role. Albeit, this structure is only influenced by districts that had existing student board representation and does not fully account for the other CORE districts of: Los Angeles, Oakland, and Santa Ana. It also is not influenced by districts other than CORE districts. Based on the success other districts have had with this model, LBUSD can anticipate similar results. Though, "success" of this system was determined by overseeing faculty rather than students or hard data. Nevertheless, the fact that this system has produced any sort of student project means it has been more successful than LBUSD in terms of student board representation effectiveness.

\section{Implications}

Schools are meant to be institutions for students. The best way to make sure that basic goal is being met is to have students hold schools and school districts accountable. No one can speak more accurately about student experience than students, and so to leave them out of the policy making process of districts, silences the largest stakeholder in the school system. Most school districts do seek out student opinion.

However, these efforts are not always effective, and so it is important to keep in mind that just sheerly having efforts in place to engage students does not necessarily mean students are actually contributing to the work of a school district. In some cases there is a lack of formal structure for student representation that allows districts to be unaccountable for engaging with students. In these cases there is no formal or mandated process that they have to go through, so sometimes nothing is done. Faulty systems can also lead to tokenism where it seems students have a voice, but that voice is so limited that it is no longer effective.

The student voice is important. It needs to be incorporated into school districts, and it should be done so in a way where students are held equal to other district representatives. Student representation, however, should not be limited to representation on a school board. Students should be included in the many avenues of policy-making and initiative implementation. That means having students on committees, boards, and project teams. For the same reason 
councilmembers have to live in the district they serve, students should be represented on the Board of Education. Adult board members cannot speak first-hand on the constituency that they represent, but students can. Student representation can be informal, but there should be a formal aspect-- a structural aspect-- to student representation as well. When educators look to serve students, they also have to include them.

\section{Recommendations}

Future research can look at gathering more student opinion on the topic. A wider range of students should be consulted, including students not involved in school and district governance and more student representatives. Researchers should also investigate school districts that do not have student board members. In this research, besides LBUSD, only schools with student Board representatives were analyzed. Ultimately, research should have the goal of implementing this system in LBUSD or similar school districts.

\section{References}

Amezcua, V. (2020, January 10). [Interview by The Researcher].

Benner, M., Brown, C., \& Jeffrey, A. (2019, August 14). Elevating student voice in education. Center for American Progress. https://www.americanprogress.org/issues/education-k-12/reports/2019/08/14/473197/elevating-studentvoice-education/

Boe video: April 17, 2019—Cue point 0, id 2357. (n.d.). Retrieved May 15, 2020, from http://www.lbschools.net/Asset/Videos/boe.cfm?videoID=2357

Boe video: February 5, 2020-Cue point 0, id 2458. (n.d.). Retrieved May 15, 2020, from http://www.lbschools.net/Asset/Videos/boe.cfm?videoID=2458

Boe video: January 8, 2020-Cue point 0, id 2450. (n.d.). Retrieved May 15, 2020, from http://www.lbschools.net/Asset/Videos/boe.cfm?videoID=2450

Boe video: January 22, 2020—Cue point 0, id 2453. (n.d.). Retrieved May 15, 2020, from http://www.lbschools.net/Asset/Videos/boe.cfm?videoID=2453

Boe video: June 10, 2019—Cue point 0, id 2366. (n.d.). Retrieved May 15, 2020, from http://www.lbschools.net/Asset/Videos/boe.cfm?videoID=2366

Boe video: March 14, 2020-Cue point 0, id 2481. (n.d.). Retrieved May 15, 2020, from https://www.lbschools.net/Asset/Videos/boe.cfm?videoID=2481

Boe video: May 1, 2019-Cue point 0, id 2359. (n.d.). Retrieved May 15, 2020, from http://www.lbschools.net/Asset/Videos/boe.cfm?videoID=2359

Boe video: May 14, 2019—Cue point 0, id 2361. (n.d.). Retrieved May 15, 2020, from http://www.lbschools.net/Asset/Videos/boe.cfm?videoID=2361

Boe video: November 6, 2019-Cue point 0, id 2419. (n.d.). Retrieved May 15, 2020, from http://www.lbschools.net/Asset/Videos/boe.cfm?videoID=2419

Boe video: October 2, 2019-Cue point 0, id 2404. (n.d.). Retrieved May 15, 2020, from http://www.lbschools.net/Asset/Videos/boe.cfm?videoID=2404 
Boe video: October 16, 2019-Cue point 0, id 2410. (n.d.). Retrieved May 15, 2020, from http://www.lbschools.net/Asset/Videos/boe.cfm?videoID=2410

Boe video: September 4, 2019-Cue point 0, id 2396. (n.d.). Retrieved May 15, 2020, from http://www.lbschools.net/Asset/Videos/boe.cfm?videoID=2396

Boe video: September 18, 2019_Cue point 0, id 2399. (n.d.). Retrieved May 15, 2020, from http://www.lbschools.net/Asset/Videos/boe.cfm?videoID=2399

California Legislative Information. (2017). School districts: governing boards: pupil members: preferential voting. Retrieved January 6, 2020, from http://leginfo.legislature.ca.gov/faces/billCompareClient.xhtml?bill_id=201720180AB261.

CORE Districts. (2020). About. CORE Districts. Retrieved May 15, 2020, from https://coredistricts.org/

CSBA. (2019, December 20). Student board members take charge at CSBA's Annual Education Conference. CSBA Blog. http://blog.csba.org/student-board-members/

Fletcher. (2002, September 5). Students on School Boards in California. Retrieved January 6, 2020, from https://soundout.org/students-on-school-boards-in-california/.

Fletcher, A., \& King, A. (2014). Sound Out Guide to Students on School Boards. https://adamfletcher.net/wp-content/uploads/2015/01/SoundOut-Guide-to-Students-on-School-Boards.pdf

LBUSD. (2020). Welcome to the Long Beach Unified School District. Retrieved January 6, 2020, from http://www.lbusd.k12.ca.us/.

LBUSD BOE. (n.d.). Long beach schools_Board of education: Board meeting videos. Retrieved May 15, 2020, from https://www.lbschools.net/Departments/Board_of_Education/videos.cfm

Lopez-Barreras, S. (2020, February 11). [Interview by The Researcher].

McAmis, K. (2020, February 7). [Interview by The Researcher].

Mills, C. (2020, January 12). [Interview by The Researcher].

Minnick, M. (2020, January 10). [Interview by The Researcher].

Prichard Committee for Academic Excellence. (2016). Students as Partners. http://prichardcommittee.org/wp-content/uploads/2016/08/Students-as-Partners-final-web.pdf

PTA. (n.d.). Job description for student board member. Retrieved May 15, 2020, from http://toolkit.capta.org/jobdescriptions/studentboardmember/

Steinhauser, C. (2020, January 31). [Interview by The Researcher].

Student X. (2020, January 21). [Interview by The Researcher].

Student Y. (2020, February 10). [Interview by The Researcher]

Youth Affairs Council of South Australia. (2016). Better Together. Youth Affairs Council of South Australia. https://officeforyouth.sa.gov.au/_data/assets/pdf_file/0008/39680/Final-Better-Together-Youth-EngagementGuide-V3-2016-02-09.pdf 
Youth Power. (n.d.). Three Models to Consider When Integrating Youth Participation into Programs. Retrieved May 15, 2020, from https://www.youthpower.org/youth-drg-toolkit-3-models-roger-hart-ladder 